A major purpose of the Technical Information Center is to provide the broadest dissemination possible of information contained in DOE's Research and Development Reports to business, industry, the academic community, and federal, state and local governments.

Although a small portion of this report is not reproducible, it is being made available to expedite the availability of information on the research discussed herein. 
LA-UR -84-1595

$$
\text { lonf }-34 \therefore 35
$$

NOTICE

POR ilONS OF THIS REFORT ACE HILI TIBLE.

has been reproduced from the best avaiiable copy to permit the broadest possitie avail. ability.

TITLE: A Model for GCR-Particle Fluxes in Stony Meteorites and

Produztion Rates of Cosinogenic Nuclides.

AUTHOR(S): Robert C. Reedy

submitted to: Proceedings of the 15th Lunar and Planetary Scierce Conference.

\section{IDISC I.AIMFR}

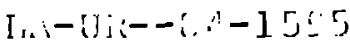

\begin{tabular}{|c|}
\hline IDISC I.AIMFR \\
\hline 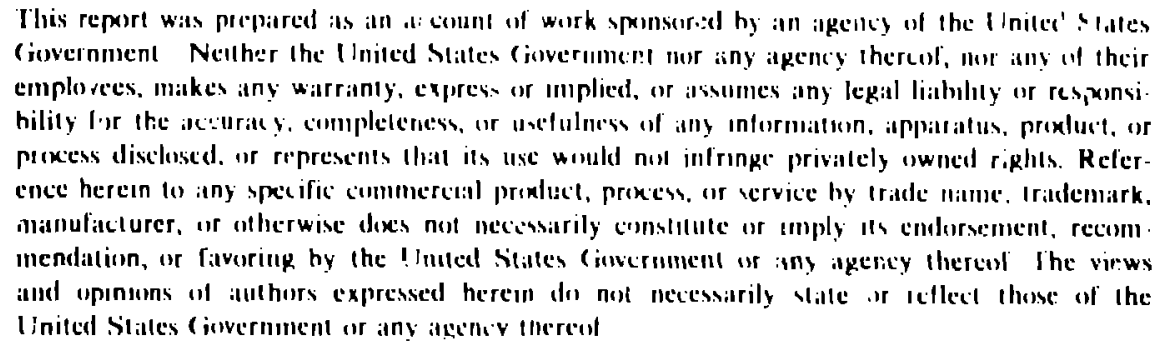 \\
\hline
\end{tabular}

$$
\begin{aligned}
& \text { : }
\end{aligned}
$$

By acceptance of this arficle. Ine publishet recognizes ithat the U S Governmant rolains a nonexclusive. royali, free license to publish or repinduce the published furm of this coniribution. or to allow others to do so. for U $S$ Governinent duiposes 


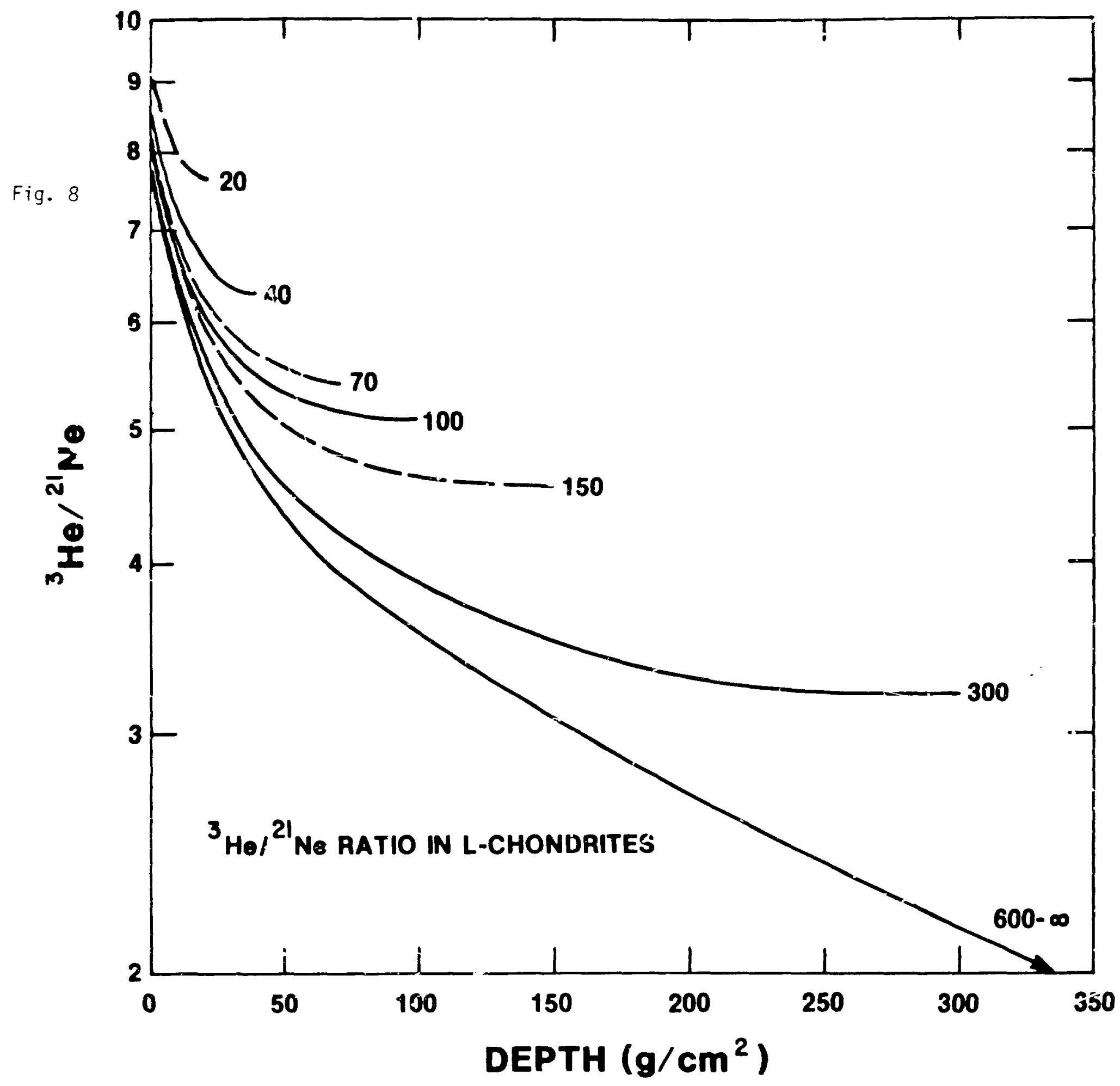


A Model for GCR-Particle Fluxes in Stony Meteorites and Production Rates of Cosmogentc Nuclides

R. C. Reedy

Los Alimos National Laboratory and Max-Planck-Institut für Chemie, Mainz, FKG

Short title: GCR-Farticle Fluxes and Cosmogenic Niclides in Meteorites 
Abstract

A model is presented for the differential fluxes of galactic-cosmic-ray (GCR) parifles with energies above $1 \mathrm{MeV}$ inside any spherical stony meteorite as a function of the meteorte's radius and the sample's depth. This model is based on the Reedy-Arnold equations for the energy-dependent fluxes of GCR particles in the moon and is an extension of tlux parameters that were derived for several meteorites of various sizes. This flux model is used to calculate the production rates of many cosmogenic nuclides as a function of radius and depth. The peak production rates for most nuclides made by the reactions of energetic GCR particles occur near the centers of meteorites with radii of 40 to $70 \mathrm{~g} \mathrm{~cm}^{-2}$. Although the model has some $11 \mathrm{mitations,} \mathrm{it} \mathrm{reproduccs} \mathrm{well} \mathrm{the}$ basjc trends for the depth-dependent production of cosmogenic nuclides in stony weteorites of various radil. These production profiles agree fairly well with measurements of cosmogenic nuclides in meteorites. Some of thes" production profiles are different than those calculated by others. The chemical dependence of the production rates for several nuclides varies with size and depth.

\author{
Int roduction
}

The ricoduction rates of cosmic-ray-produced nuclides in motcortlie samples vary with the motoorito's size and shape and with the sarele's location. These rhanges in the production rates as a function of a simple's shiclding condition result from the vartations of the fluxes of primary and srecondary cosmic-ray particles inside a moteorite. As the primary particles 
in the cosmic rays penetrate a meteorite, they are removed and secondary particles, especially neutrons, are produced and are subsequently removed. Botin the flix of cosmic-ray particles and the energy spectral shape of these particles change inside a meteorite. Cosnog znic nuclides are made by primary and secondacy particles with energies that are determined by the nuclear reactions producirig a nuzlide.

Mary investigations of the variations of the cosmlc-ray flux or of the history of a meteorite's cosmic-ray exposure require good shielding-dependent production rates [keedy et al., 1983]. For example, the irradiation histories of Shergotty, Nakhla, Chassigny, and other SNC meteorites are important in establishiag whether these ubjects came from Mars and, if so, when ard how they wore ejected [Bogard et al., 1984]. Repurtec here is a model for the fluxes of primary and secondary galactic-cosmic-ray (GCR) particles as a function of depth in spherical mezeorites of any radius. These fluxes are used to calculate the producticn rates of several cosmogenic nuclides in L-chondrites. 'lhis model can be used to calculate the production rates of many nuclides in stony meteoricic samples nf any chemical composition. Tho production of nuclides by the solar ccemlc rays (SCR) is not considered here because the surface layers wiere SCR effects are important are usually removed by ablation when a meteorite passes tinrough the earth's atmosphere; however, SCk-produced nuclides are probably pree nt in certain metcoritic samples [M1chol et al., 1982].

The variations in the concentrations of cosmogenic nuclides in a meteorite were first studied in detail in the slabs of several large iron moteorites. Signer and Nier [1960] uged thitr measurenents for the cosmogenic 
noble gases in the iron meteorite Grant to obtain a semi-empirical model for nuclide production as a function of radius and depth. Arnold $\in$ al. [1961] estimated the differential energy spectra of cosmlc-ray particles for two different depths in iron meteorites and calculated the production rates of cosmogenic nuclides by using cross sections for the main reactions. Kohman and Bender [1967] used the measured distributions of radionuclides in thick targets of iron bombarded by beams of high-energy protons to model radius- and depth-dependent production rates.

The varlations in the production rates and ratios of cosmogenic nuclides were first investigated in stony meteorices by comparing various production rates or ratios measured for a number of different meteorites. For example, the $\dot{\mathrm{He}}_{\mathrm{He}}{ }^{2 \mathrm{l}} \mathrm{Ne}$ and ${ }^{22} \mathrm{Ne} /{ }^{21} \mathrm{Ne}$ ratios in many stc ies varled, but the ${ }^{3} \mathrm{He} /{ }^{21}$ Ne ratios showed a systematic trend with the ${ }^{22} \mathrm{Ne} /{ }^{2 l} \mathrm{Ne}$ ratios; most fell near a correlation 11ne [Eberhardt et al., 1966]. The isotope ratio ${ }^{22} \mathrm{Ne} /{ }^{21} \mathrm{Ne}$ has been lised for empirtcally determined shiclding-corrected production rates lfor example, Nishilzumi et al., 1980l, but this ratio does not uniquely determine the sample's exact exposure geometry or a nuclide's production rate. Somo pioduction rates in stony meteorites were calculated as a fiction of size and depth by Trivedi and Goel $|1973|$ using thick-target results for silfcate targets and the model of Kohman and Bender I1967/ but only for the radionuclides ${ }^{3} \mathrm{H}$ and ${ }^{22} \mathrm{Na}$. Nyquist [1984] has extended the semf-empirical model of Stgne: and Nier [1960] to chondrites for several noble-gas isotopis.

Recedy and Arnold [1972] applied the flux and cross-section approach of Armeld et al. [196]J to the moon and derived a new exprassion for the flux ol Ce, particlos with encrgies below 100 MeV. The depth-dependent variali ins of 
cosmogenic nuclides in meteorites have been studied by measuring samples with docunented locations from cores (such as Keyes and St. Severin) or large fragments (for example, Jilin) of a meteorite. These activity-versus-depth results have been used by keedy et al. [1978, 1979] and Bhattacharya et al. [1980] to determine specific sets of flux parameters for these meteorites. The equations for the GCR-particle spectra that were used for these meteorite models are the lunar ones of Reedy and Arnold [1972]. The model reported here generalizes these and other flux-parameter sets for several meteorites to get expressions for the depth-dependent GCR flux in meteorites of ary radius.

Model for GCR-Particle Fluxes in Meteorites

This new meteorite GCR-particle flux model is based on the model teveloped by Reedy and Arnold [1972] for the moon. The Reedy-Arnold model uses two variables: a flux normalization and a spectral-hardness paraneter, $\alpha$ For spherical stony meteorites, the flux normalization is calculated using the interaction and other parameters of Reedy and Arnold [1972] and an omnidirectional integral flux above $1 \mathrm{GeV}$ of 1.87 protons $\mathrm{cm}^{-2} \mathrm{~s}^{-1}$ |Reedy et al., 19791. This flux is $10 \%$ hlgher than that used by Keedy and Arnold [1972] for $1 \mathrm{AU}$ but is only $4 \%$ higher than a more recent estimate [Reedy, 1983] of the average GCR proton integral flux above $1 \mathrm{GeV}$ at $1 \mathrm{AU}$. The flux of GCR particles to which a metcorite is exposed should be a little higher than that at $1 \mathrm{AU}$ because the flux increases with distance from the sun at the rate of about 2 to $3 \%$ per AU [for example, Mckibben et al., 198\%) and metcoritos probably recelve most of their cosmic-ray exposure at 2 to $3 \mathrm{AU}$ from the sun. These fluxes are the average over an ll-year solar cycle; the actual 
GCR-particle flux above $1 \mathrm{GeV}^{\text {nucleon }}{ }^{-1}$ near $1 \mathrm{AU}$ varies by a factor of about two over a solar cycle [Reedy, 1983].

The integral fluxes of GCR particles with energies above $1 \mathrm{GeV}^{\text {nucleon }}{ }^{-1}$ that were calculated as a function of depth in meteorites of various radii are shown in Figure 1. The shapes of these fluxes versus depth curves show the effects of an omnidirectional source of primary GCR particles. The fluxes of GCR-particles inside meteorites chanre slowly near the centers of spherical meteorites and vary most rapidly near the surface. Even for fairly large meteorites, these fluxes are considerably above those for the same depth in a semi-infindte slab (an infinite radius).

The model of Arnold et al. [1961] used the expression $(E+a)^{-2.5}$ for the GCR-particle spectral shape above $100 \mathrm{MeV}$. The model of Reedy and Arnold [1972] kept this spectral expression above $100 \mathrm{MeV}$, but it had new equations for the differential flux of GCR-particles with energies below 100 MeV that changed shape as the spectral-hardness parameter a changed. The Reedy and Arrold [1972] expressions for the fluxes of GCR-particles as a function of energy were used for meteorites by Reedy et al. [1978, 1979] and Bhattacharya et al. $\{1980]$. For the meteorites studied by these investigators, curves of $\alpha$ versus depth were derived to fit the cosmoginic-nuclide measurements. However, only a few bpeciflc sets of a curves were derived, and no generalizations or expressions for spectral hardness were developed for ather meteorites.

An cxpression for the spectral-hardness parameter as a function of ne:corte radtus $R$ and sample depth $d, \alpha(R, d)$, has been developed by fitting four cases: $R=0,70$, and $300 \mathrm{~g} \mathrm{~cm}^{-2}$, and an infinite radius. $A$ value of 
$a=9 / 4 \mathrm{MeV}$ gives a very crude approximation to the primary GCR spectrum (or $R=0)$. : te a curve for St. Severin [Recdy et al., 1979] was used for $\mathbf{R}=70 \mathrm{~g} \mathrm{~cm}^{-2}$. The lunar a curve [Reedy and Arnold, 1972] was used for an Infinite radius. The $\alpha$ curve for $R=300 \mathrm{~g} \mathrm{~cm}^{-2}$ was determined by fitting che ${ }^{22}$ Na activities measured for depths of 15 to $50 \mathrm{~cm}$ in Jilin (which was formerly called Kirin) (Heusser and Ouyang, 1981; G. Heusser, personal communication, 1982]. The ${ }^{22} \mathrm{Na}$ activities in Jilin are falrly constant for these depths, unlike the predictions of I'rived1 and Goel [1973], which show a strong drop with increasing depth for a meteorite of that radius. The a versus depth curves for these four cases are fairly well determined. Using these four curves, a relation was derived that fits these radil and that can be used for other radii.

The gencralized equation for $\alpha(R, d)$ is

$$
a(R, d)=f(R) *_{R A}(d)+b(R) * \alpha_{R A}(2 R-d)
$$

where $\alpha_{R A}(x)$ is the Reedy and Arnold ! 1972] value of $\alpha$ at a depth $x$ in the moon, and $f(R)$ and $b(R)$ are parameters representing particles coming from the front and back of a meteorite of radius $R$. For $x>80 \mathrm{~g} \mathrm{~cm}-2, \alpha_{R A}(x)=$ $324.44 \star \exp (-0.004838 x)$. The original a curve of Reedy and Arnold [1972] only had this : pe for $80<x<350 \mathrm{~g} \mathrm{~cm}^{-2}$ and approached a constant value of $a=$ $50 \mathrm{MeV}$ at a depth of $500 \mathrm{~g} \mathrm{~cm}^{-2}$. Data for cosmogentc nuclides deep in the moon and in Jilin suggest that a should continue to decrease roughly exponentially below $350 \mathrm{~g} \mathrm{rm}^{-2}$. The parameter $\mathrm{f}(\mathrm{R}) 1 \mathrm{~s} 0.78$ for $\mathrm{k}<64 \mathrm{~g} \mathrm{~cm}^{-2}$ and

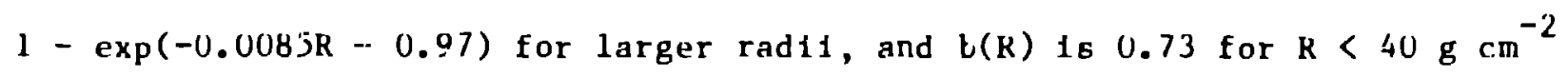


and $0.65+0.002 R$ for greater radil. For very large radii, $\alpha(R, d)$ is assumed to be the same as $\alpha_{R A}(d)$.

Several spectral-hardness curves calculated with the above expression are shown in Figure 2. The a versus depth curves for $R=70$ and $300 \mathrm{~g} \mathrm{~cm}^{-2}$ reproduce very well the or Iginal curves derived for St. Severin and Jilin. When compared to the curves in Bhattacharya et al. [1980], these a(I.,d) values are all similar in shape but are higher than their valurs for $R$ of $15 \mathrm{~cm}$ and greater. As in the case of flux normalization curves in Figure 1 , chese curves for a as a function of depth are fairly constant near the centers of spherical meteorites. The a profiles for radii above about $600 \mathrm{~g} \mathrm{~cm}^{-2}$ are very nearly that for a slab. Because the largest meteorite used in obtainiug these curves had a radius of $300 \mathrm{~g} \mathrm{~cm}^{-2}$, there could be some uncertainties in these a versus depth curves for very large radi1. However, the absoluts flux of particles, not the spectral shape, controls the production of cosmogenic nuclides in very large metcorites.

Calculated Production Rateís

Calculated production rates for several cosmogenic nuclides as a function of depth in spherical L-chondrites of various radii are shown in figures 3 7. For ${ }^{26} \mathrm{Al}$, the cross sections of Reedy and Arnold [1972] were used. For ${ }^{10}$ Be, new cross sections were used that give good fits to experimental profiles in cores from St. Severin and the moon [Tuniz et al., 1984]. Cross sections for the production of the light noble-gas 1sotopes of ${ }^{3} \mathrm{He},{ }^{21} \mathrm{Ne}$, and ${ }^{36}$ At were from Reedy [1981], Reedy et al. [1979] and Hohenberg ot al. i1978]. 
respertively. The rates for ${ }^{3}$ He have been multiplied by a factor of 1.4 to get the proper ${ }^{3}$ He production rates [Reedy et al., 1978; Reedy, 1981]. The profiles in these figures show the effects of the build-up of sccondary neutrons and the attenuation of primary and, eventually, secondary particles. These calculations reproduce fairly well the measurements of cosmogenic nuclides in meteoritic samples. The shapes of these production profiles are qualiratively similar to those of previous calculations, but there are some signilicant differences.

'The ${ }^{21}$ Ne production profile calculated here for $R=70 \mathrm{~g} \mathrm{~cm}^{-2}$ is the same as that in Reedy et al. [1979], which gave a fairly good fit to the measured data ${ }^{21}$ Ne for St. Severin [Schultz and Signer, 1976]. The calculated profile for ${ }^{53} \mathrm{Mn}$ in St. Severin had the same shape as that measured by Englert and Hex [1980]. The calculated and measurea ${ }^{10}$ Be profiles in St. Severin agreed fairly well [Tuniz et al., 1984]. The ondy test for a meteorite with a radius of $300 \mathrm{~g} \mathrm{~cm}^{-2}$ is to use ${ }^{22} \mathrm{Na}$ for depths of about 50 to $185 \mathrm{~g} \mathrm{~cm}^{-2}$ in Jilin [G. Heusser, personal communication, 1982]. The calculatec production profile for ${ }^{22} \mathrm{Na}$ is similar to thuse of ${ }^{26} \mathrm{Al}$ ard ${ }^{38} \mathrm{Ar}$, and the activity of ${ }^{22} \mathrm{Na}$ should drop near the center of Jilin. Sajples from the center of Jilin were recently obtained [Heusser et al., 1983] and ${ }^{22} \mathrm{Na}$ measurements are being made, which will provide an addjtional test of this model for large meteorites.

The calculated production profiles for ${ }^{3} H$ and ${ }^{22}$ Ná are similar to thos' of Trivedi and Gocl [1973] for $R<100 \mathrm{~g} \mathrm{~cm}^{-2}$, but for larger radil the profiles calculated here drop much slower with increasing depth than do theirs. The Trivedi and Goel [1973] profile for ${ }^{22}$ Na gives a very pror fit to the ${ }^{22} \mathrm{Na}$ measured in Jilin [G. Heusser, personal communication, 1982]. The Trivedi-Goel profile for ${ }^{3} \mathrm{H}$ in a meteorite of infinite radius decreases with 
depth at twice the rate calculated here and by Reedy and Arncidd [1972]. Nyquist [1984] compared the results for ${ }^{3} \mathrm{He}$ and ${ }^{21} \mathrm{Ne}$ in chondrites from his semi-empirical model with those for this model. The basic trends are similar, but there are some minor differences. For example, Nyquist's model doesn't have an ircrease for ${ }^{3}$ He production with depth wear the surface, but such an 3 inc 1ncrease with depth was cbserved for St. Severin [Schultz and Signer, $1976]$.

The calculated ratios of ${ }^{3} \mathrm{He} /{ }^{21} \mathrm{Ne}$ as a function of rauius and depth are shown in Figure 8 . Most of the ${ }^{3} \mathrm{He} /{ }^{21} \mathrm{Ne}$ ratios measured for meteorites are between 3 and 8 , which is the region of Figure 8 that corresponds to typical meteoroid radil The calculated curves of ${ }^{3} \mathrm{He} /{ }^{21} \mathrm{Ne}$ versus ${ }^{22} \mathrm{Ne} /{ }^{2]} \mathrm{Ne}$ for different radii all fall along a single line, whereas the results for this ratio in meteoritic cores plot as a line [for example, Schultz and Signer, 1976], but at a slight angle to the Eberhardt et al. [1966] trend 1ine. Som!. of this deviation in the core data from the trend line could be due to SCRproduction, but most of the divergence is probably real. Any model like the present one with just one parameter for the spectral shape will only give a single line for the ${ }^{3} \mathrm{He} /{ }^{21} \mathrm{Ne}-\mathrm{versus}-{ }^{22} \mathrm{Ne} /{ }^{21} \mathrm{Ne}$ plot for different radii. The fact that the core data do not deviate much from the main trend line indicates that the present model is not a bad approximation. plots for many radil of the calculated ${ }^{22} \mathrm{Ne} /{ }^{21} \mathrm{Ne}$ ratio versus a calculated production rate look similar to those of Nishizumi et al. [1980] for $\mathrm{R}<200 \mathrm{~g} \mathrm{~cm}^{-2}$, but for larper radif almost any production rate is possible for the smallest values of the. 22 Ne/ $2 \mathrm{I}_{\mathrm{Ne}}$ ratio. 
In Figures 3 to 7 , the polnts plotted for pure GCR primary protons were calculated with the spectrum of Reedy [1983] and are about 0.5 of those calculated with $\alpha(C, 0)$. This model is probably not very accurate for $R<20 \mathrm{~g}$ $\mathrm{cm}^{-2}$ because it most likely overestimates the number of secondary neutrone. For such small obiects, a signiflcant faction of the low-energy particles are protons, whereas this model, like thet of Reedy and Arnold [1972], assumles that the low-erergy particles are predominately neutrons. A model that explicitly considers neutrons and protons and their corresponding crofss sections separately is needed for such small meteorites. I also suspected that the radii for this model really refer to meteorold radii that are about 5 $\mathrm{g} \mathrm{cm}^{-2}$ greater than the nominal value of. $R$.

\section{Discussion}

The model rresented here for the fluxes of GCR particses in meteorites is a generallzation of presious results for several meteorites. It can be used to calcu?ate the production rates of a varley of cosmogenic nuclidcs in samples at ary defth in spherical stony ruetcorltes of different radii. The use of the spectral model of Reedy and trnold i1972], which has only une free shape parameter, is probably too simple an approach, but it does give reasonable production rates for a range of radid. For most meteorites, which have radil between about 40 and $300 \mathrm{~g} \mathrm{~cm}^{-2}$, this model is fatrly good. It most lil.cly iz not very good for sinaller melcorites. The flux normalization, which controls the production rates of cosmegenic nuclides more than does the spectral-hardncss parameter, is relatively good for larger radif. 
Calculations for the production rates of cosmogenic nuclides in stony meteorites agree fairly well with measur-ments. Unfortunately, only several cosmogenic nuclides measured in the cores or ruain masses of $f$ ust a few meteorites were used in deriving this model additionil neasurements for documented locations in other meteorites a:e needed to verify ard refine this model. The calcuiated production rates a'sreed falrly well with other calcuLations, but several inajor discrepancies exist. For most of the disagreements among the predictions of these models, :he results of the present calculations agree batter with measurements.

This model was used by Reedy [1984] to calculate the production rates of cosmogenic noble gases in six differint SNC meteorites. The production rates of ${ }^{21}$ Ne and ${ }^{38}$ Ar varied wil':ly among these achondrites because of their viry different chemistries. For these and some other nuclides in several of these SNC meteorites, the production rates relative to that for the same exposure' geometry in an L-chondrite varied witi sample depth and was not just a function of chemistry only. These depth-dependent ratios for different chemistries result when a product is made by at least two reactions, one of whic! is Induced by GCR particles with energies considerably different tlan those Inducing the othei reartions, for example, the production profile of 38 Ar from calcium (invelving mainly low-encrgy pasticlos) is differcnt than that of ${ }^{38}$ Ar from Iron (a high-energy reaction). The ratio of ${ }^{36}$ Ar produrtion from calclum to that from iron can increase by a factor of two from the surface to the center of a large metcorte.

Ihrese races for production of spallogenic nuclides by GCR particles as a furirtirn of depth and radius are probably a falty good cepresentat ton of the 
true systematics in spherical stony meteorttes. They change most rapldly at the surface and approach a ronstant production rate in the centers of spherlcal meteorites. These production rates cover a wide range of values over the possible meteorite radii and sample depths. They are not simply twice the value for a biat geometry. Using only spallogenic nuclides, it is very harf to determine uniquely where a sample was irradiated and the size of the meteorite. However, ratios $11 \mathrm{ke}{ }^{3} \mathrm{He} /{ }^{21} \mathrm{Ne}$ can be used in many cases to restrict the range of possible production rates for a cosmogenic nuclide. To best unfold the exposure history of a meteorite, measirements of many different products that are made by the cosmic rays with a variety of production profiles are needed for several samples from known locations. Such extensive sets of mcasurements will not only improve our und-rstanding of the production systematics of cosmogenic nuclides, but will also help define possible cosmic-ray variations and deturmine the origin and evolution of metenrites.

Acknowledgments

I wish to thank G. Heussır for his unpublished results for cosmogenic: nuclides in Jilin. L. Nyyuist prostded comparis lls of the results of his model with my calculations. Much of tho work presented here was done while I was a guest scientist at the Max-Planck-Institut für Chemie in Mainz, Federal Republic of Gorinany; I would like to thank F. Bcgemann, L. Schultz, and H. Wänke for their hosplinjity and the Max-l'lanck Gasellschaft for partial 
support while I was there. Some of this work was supported by NASA and done In Los Alamos under the auspices of the U.S. Department of Energy.

\section{References}

Arnoid, J. R., M. Honda, and D. Lal, Recurd of cosmic-ray intensity in the metcorites, J. Geophys. Kes., 66, 3519-3531, 1961 .

Bhattacharya, S. K., M. Inanura, N. Sinha, and N. Bhandari, Depth ait size

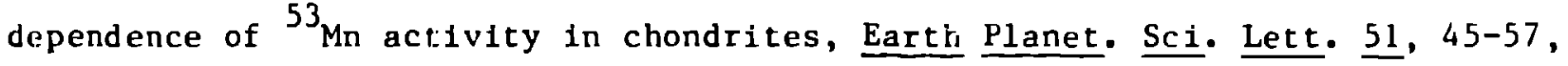
1980.

Bogard, D. D., L. E., Nyquist, and P. Johnson, Noble gas contents of shergottices and fmplfcations for the Martian origin of SNC meteorites, Ceochim. Cosmochjm. Acta, in press, 1984.

Eberhardt, P., J. Eugster, J. Geiss, and K. Marti, Kire gas moasuremints in 30 sione mitcorites, Z. Naturforschg., 21a, 414-426, 1960.

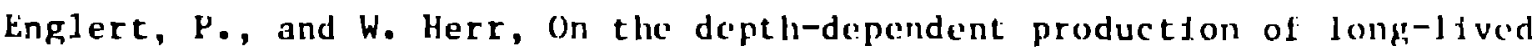
spallogenic ${ }^{53}$ Mn in the St. Severin chondrite, Earth Planot. Sci. Lute., 47. $361-369,1980$.

Heusser, G., T. KJrsten, and Z. Guyang, Drili core probings of thu JidIu chondrite (abstract), Metooritics, 18, J12, 1983. 
Heusser, G., and Z. Ouyang, Kirin, its irradiation ages and the reconstruction of 1ts preatmospheric size (abstract), Meteorit1cs, 16, 326-327, 1981.

Hohenberg, C. M., K. Mart1, F. A. Podosek, R. C. Reedy, and J. R. Shirck, Comparisons betwa'n observed and predicted cosmogenic noble gases in lunar samples, Proc. Lunar Planet. Sci. Conf. 9th, 2311-2344, 1978.

Kohman, T. P., and M. L. Bender, Nuclide production by cosmic rays in meteorites and on the moon, in High-Energy Nuclear Reactions in Astrophysicis, edited by B. S. P. Shen, pp. 169-245, W. A. Benjamin, New York, 1967.

McKibben, K. B., K. R. Pyle, and J. A. Simpson, The galactic cosmlc-ray intensity gradient and large-scale modulation in the helinsphere, Astrophys. J., 254, L23-L27, 1982 .

Mlchel, R., G. Brinkmann, and R. Stück, Solar cosmic-ray-produced radionuclides in meteorttes, Earth planet. Sci. Lett., 59, 33-48, 1982.

Nishifzumf, K., S. Regnier, and K. Mart1, Cosmic ray ixposure ages of chondrites, pre-jrradiation and constancy of cosmic ray flux in the past, Earth planet. Sc1. Lett., 50, 156-170, 1980.

Nyqutst, L. E., Semi-cmpirical model for tipallogente He alld Ne in chondrites: Implications for irradiation history of SNCs (abstract), In Lunar and Plancetary Sc1ence XV. pp. 613-614, The Lunar and Planctary lnstitute, llouston, 1984. 
Reedy, R. C., Cosmic-ray-produced stable nuclides: Var1ous production rates and their 1mplications, Proc. Lunar Planet. Sc1. Conf. 12th, 1809-1823, 1981.

Reedy, R. C., Nuclide production by primary cosmlc rays in very small objects (abstract), Meteoritics, 18, 383-384, 1983.

Reedy, R. C., Calculated production rates of noble gases in the SNC meteorites (abstract), in Lunar and planetary Scife.sce XV, pp. 677-678, The Lunar and Planetary Institute, Houston, 1984.

Reedy, R. C., and J. K. Arnold, Interaction of solar and galactic cosmic-ray particles with the moon, J. Geophys. Res., 77, 537-555, 1972.

Reedy, R. C., J. R. Arnold, and D. Lal, Cosmic-ray record in solar system matter, Ann. Re'v. Nuc1. Part. Sc1., 33, 505-537, 1983.

Reedy, R. C., G. F. Herzog, and E. K. Jessberger, Depth variations of spallogente nuclides in meteorites (abstract), in Lunar and Planetary science IX, pp. 940-942, The Lunar and Planclary lnstitule, Houston, 1978.

Reedy, R. C., G. F. Herzol, and ḱ. K. Jesuberger, The reaction Mg(n, $\alpha)$ Ne at 14.1 and $14.7 \mathrm{MeV}:$ Cross gections and Impltations for moleorites, Earth p1anet. Sict. Lett., 44, 341-348, 1979.

Schultz, L., and P. Signer, Depth dependerece of spillogente hellum, neon, and

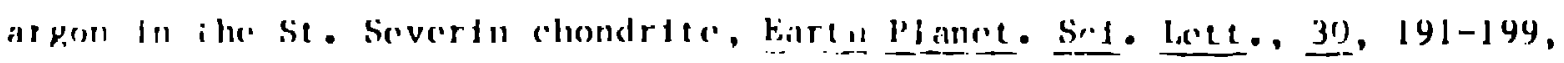
$19 / 6$. 
Signer, P., and A. O. Nier, The distribution of cosmic-ray-produced rare gases In Iron meteorites, J. Geophys. Res.., 65, 2947-2964, 1960.

Trived1, B. M. P., and P. S. Goel, Nuclide production rates in stone meteorites and lunar samp.es by galactic cosmic radiation, J. Geophys. Res., $\underline{78}, 4885-4900,1973$.

Tuniz, C., C. M. Smlth, R. K. Moniot, T. H. Kruse, W. Savin, D. K. Fal, G. F. Herzig, and R. C. Reedy, Beryllium-10 contents of core samples from the St. Severin meteorite, Geochim. Cosmochim. Acta, in press, 1984.

R. C. Reedy, Nuclear Chemtstry Group, MS-J514, Los Alamos National Laboratory, Los Alamos, NN 87545.

FIGUKE CAPTIOR.S

F1g. 1. The calculated fluxes of Grk particles with energies above $1 \mathrm{G}: \mathrm{V}$ nucleon ${ }^{-1}$ as a function of depth for meteorites of various radil. The $x$ is the omnidirectional incident flux of primary GCR particles in space to which the meteorites were assumed to be exposed.

Fig. 2. The spectral-hardness parameter $a(k, d)$ as a function of sample depth for several metcorold radif $\left(1 \mathrm{n} \mathrm{cm}^{-2}\right)$. The vilues of a for the centers of metcorites with fintermediate radil are indicated with $x$. 
Fig. 3. Calculated production rates of ${ }^{26} \mathrm{Al}$ as a function of depth in L-chondrites of several radil. The radil are 1 . $\mathrm{g} \mathrm{cm}^{-2}$ and an infinite radius corresponds to a semi-infinite plane or a slab. The $x$ marks the production rates for pure GCR primary protons calculated with the average frimary GCR-proton spectrum of Reedy [1983].

Fig. 4. Calculated production rates versus depth for ${ }^{10}$ Be in L-chondrites. See caption for Figure 3 for more detalls.

Fig. 5. Calculaied production rates versus depth for ${ }^{3}$ He in L-chondrites. See caption for Figure 3 for more detalls.

Fig. 6. Calculated production rates versus depth for ${ }^{21}$ Ne in L-chondrites. Sec caption for Figure 3 for more details.

Fig. 7. Calculated production rates vereus depth for ${ }^{38}$ Ar in Luchondrites. See caption for Figure 3 for more detalls.

Fig. 8. The calculated ${ }^{3}$ He/ ${ }^{2}$ Ne retio as a function of depth in L-chondrites of verious radi1. A ratio of 16.3 was calculated for the primary GCR protons using the spectrum of Recdy [198:3]. 


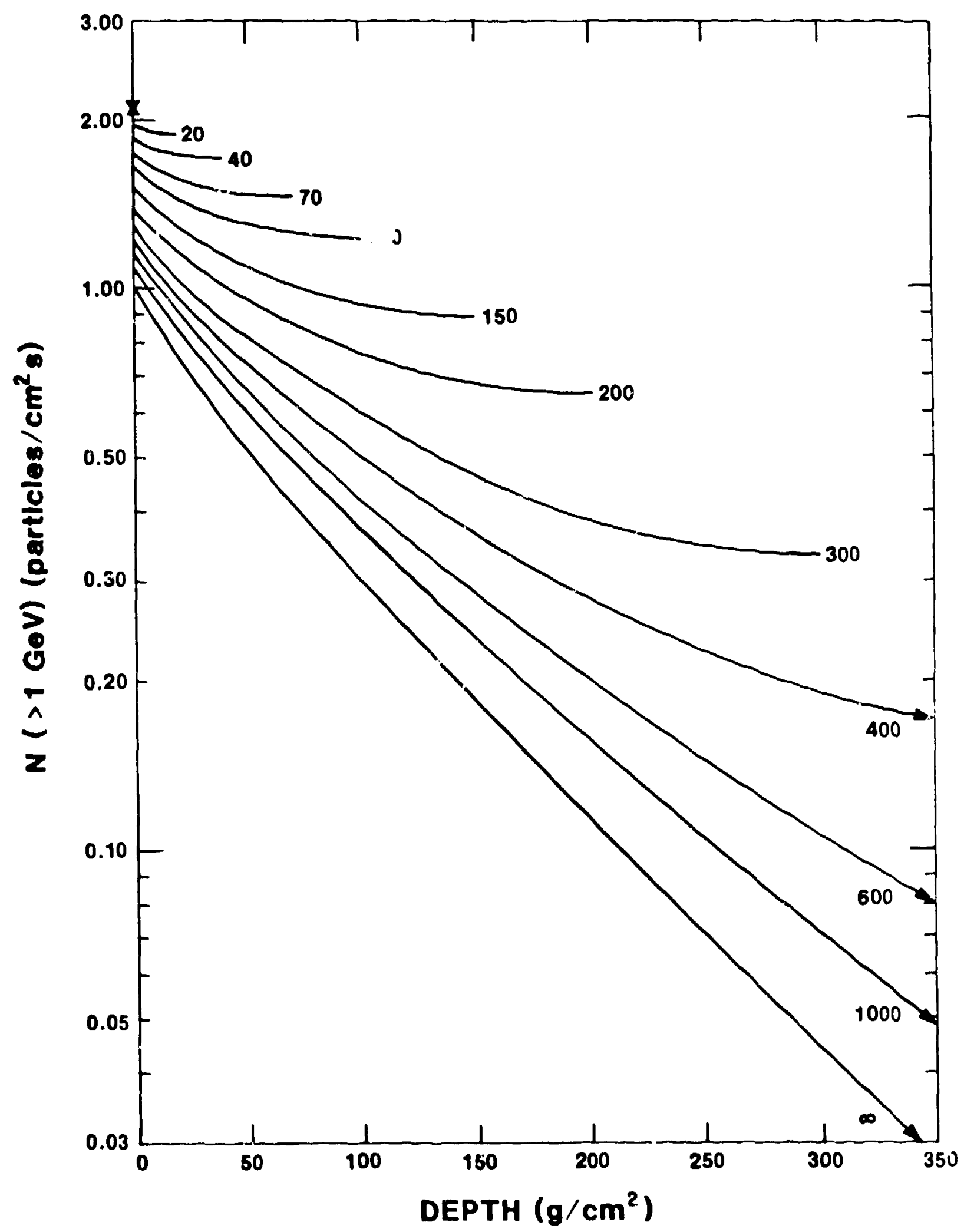

Fig. 1 


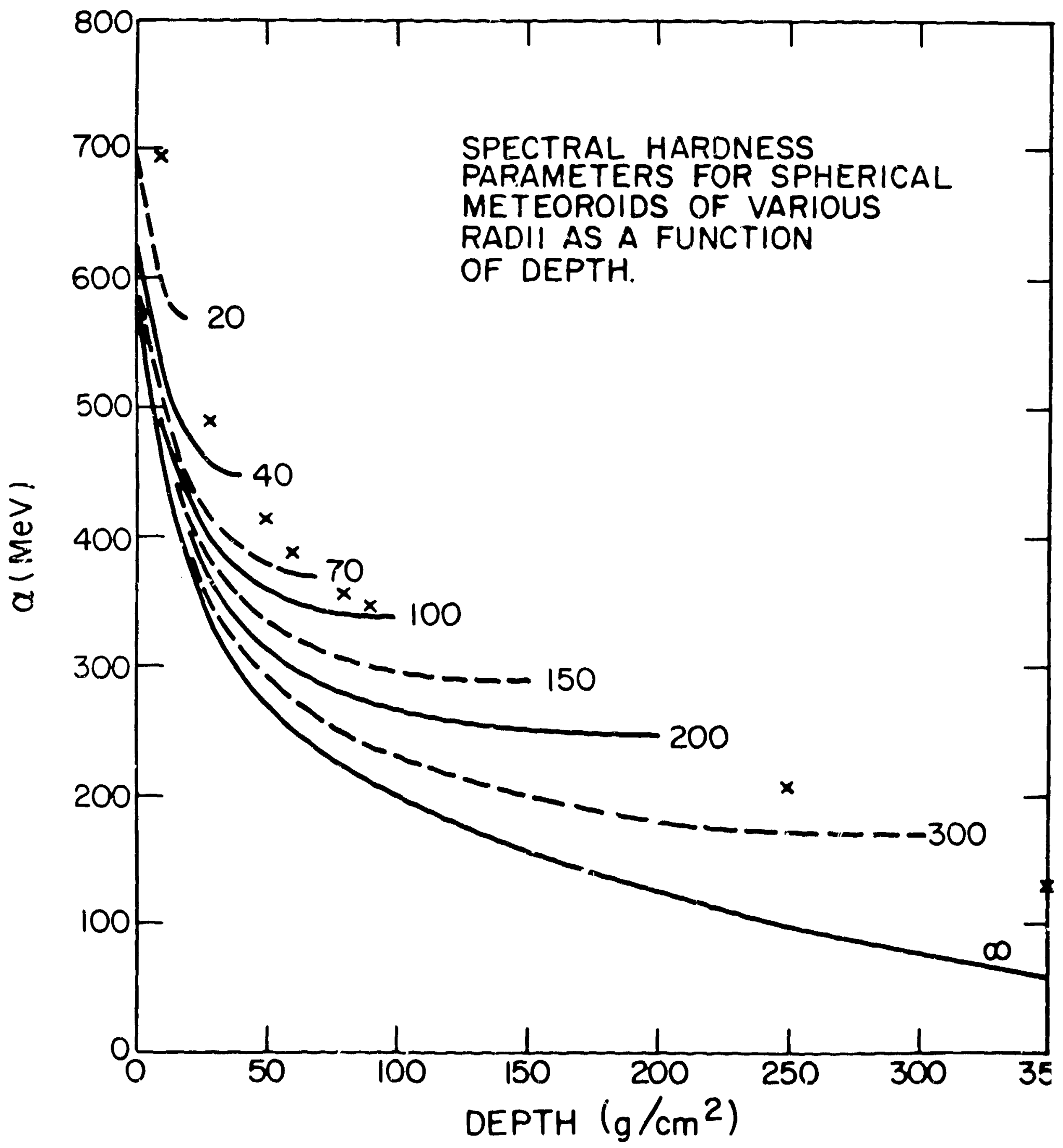

Fig. 2 


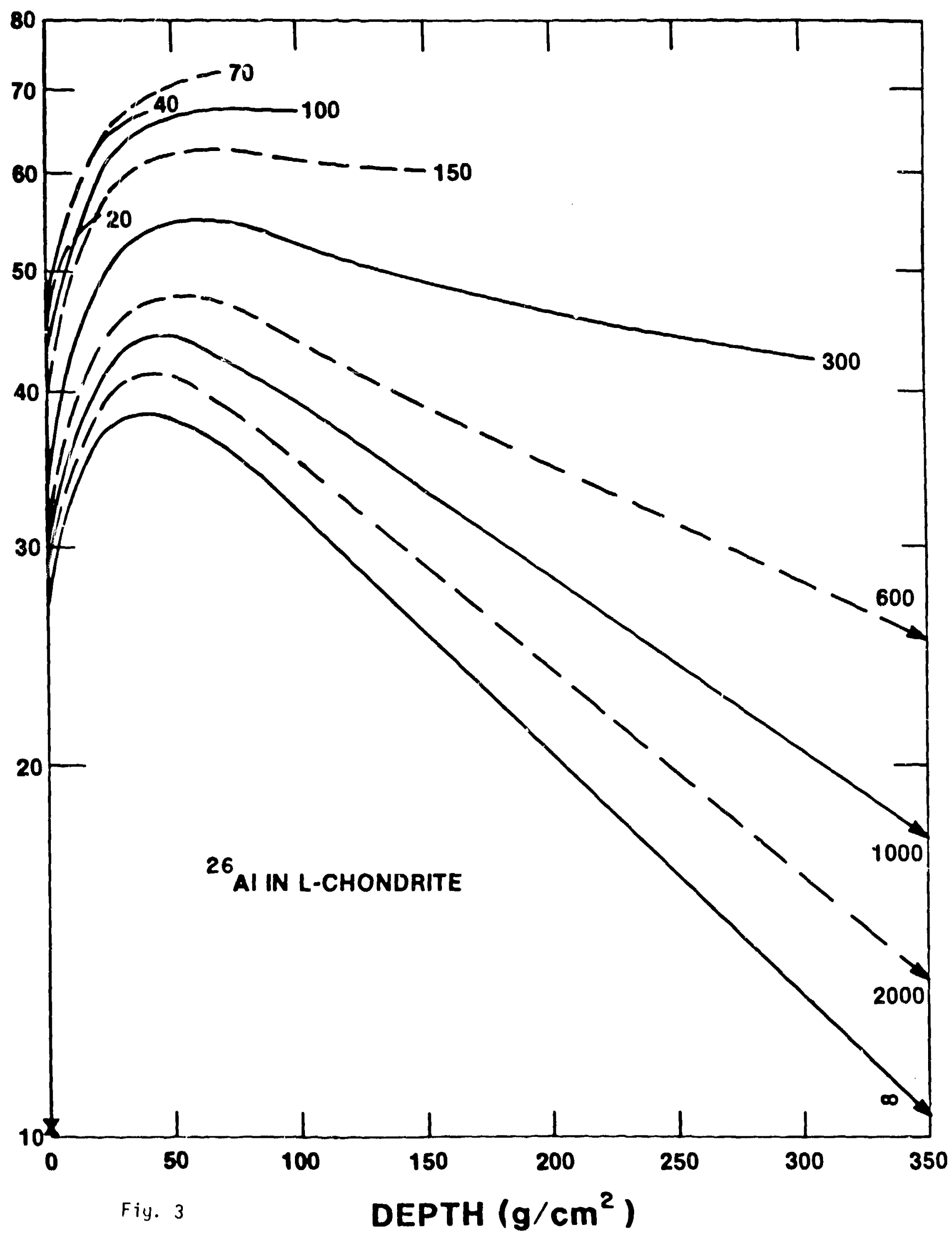




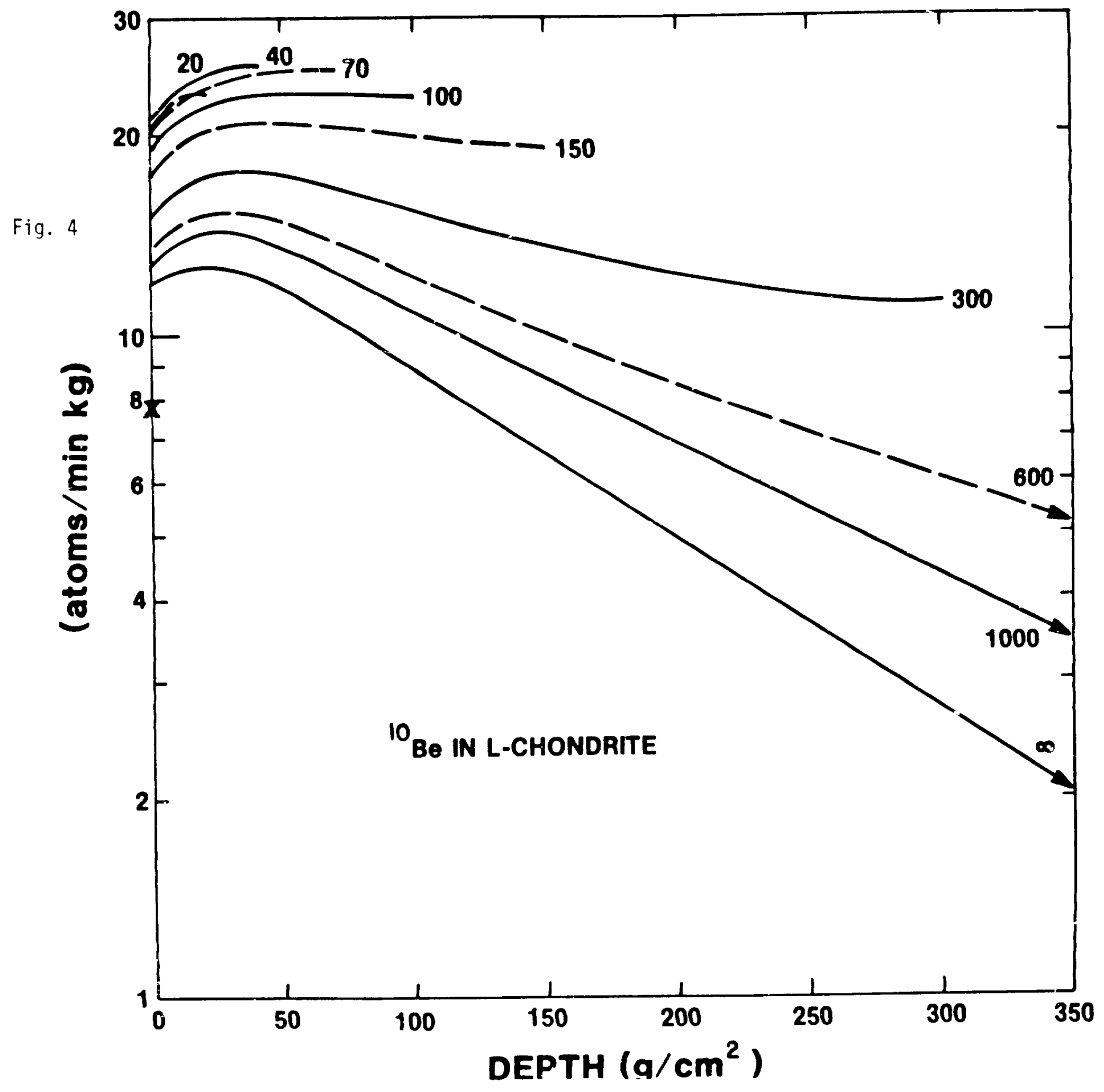




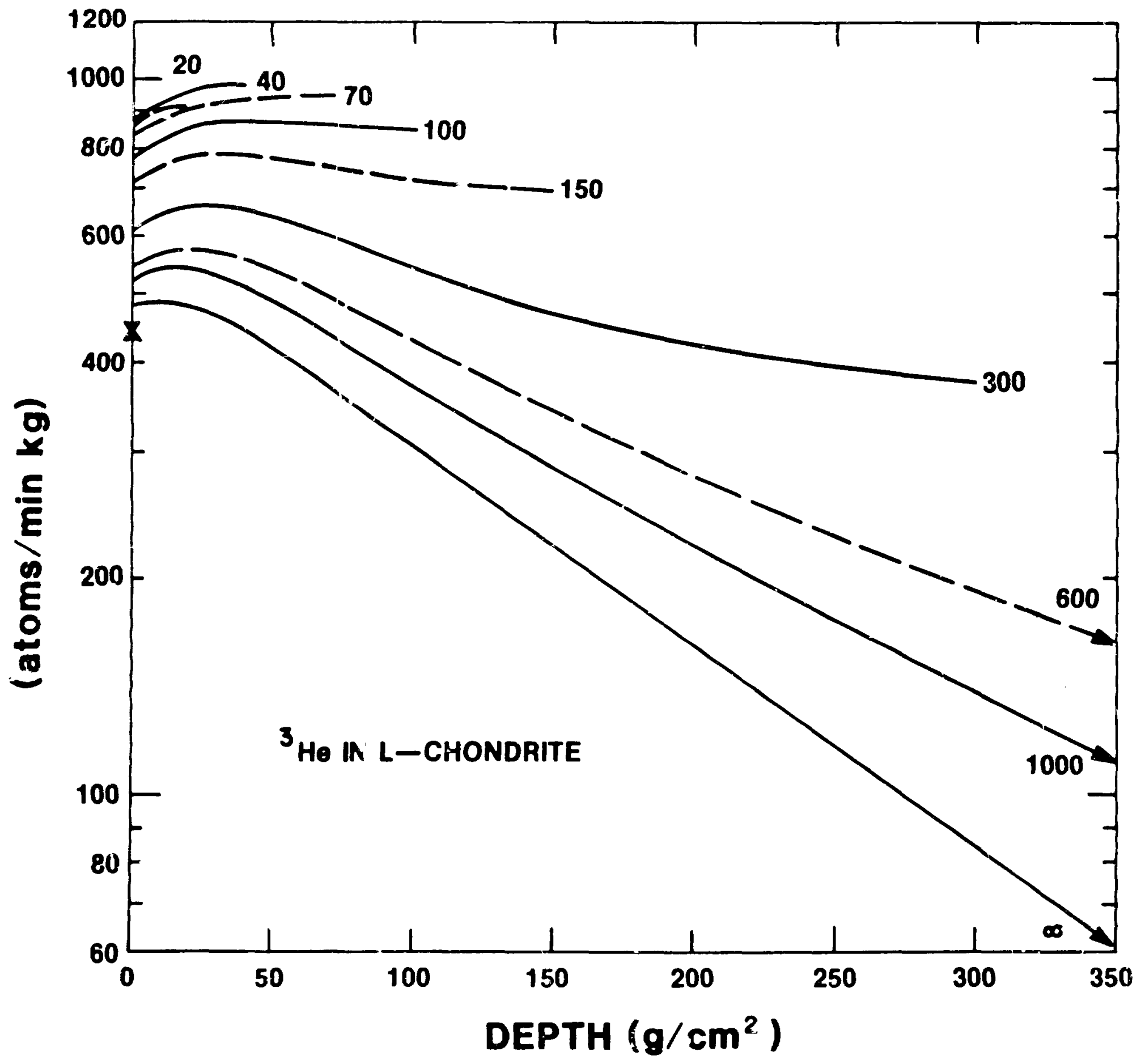

rig. 5 


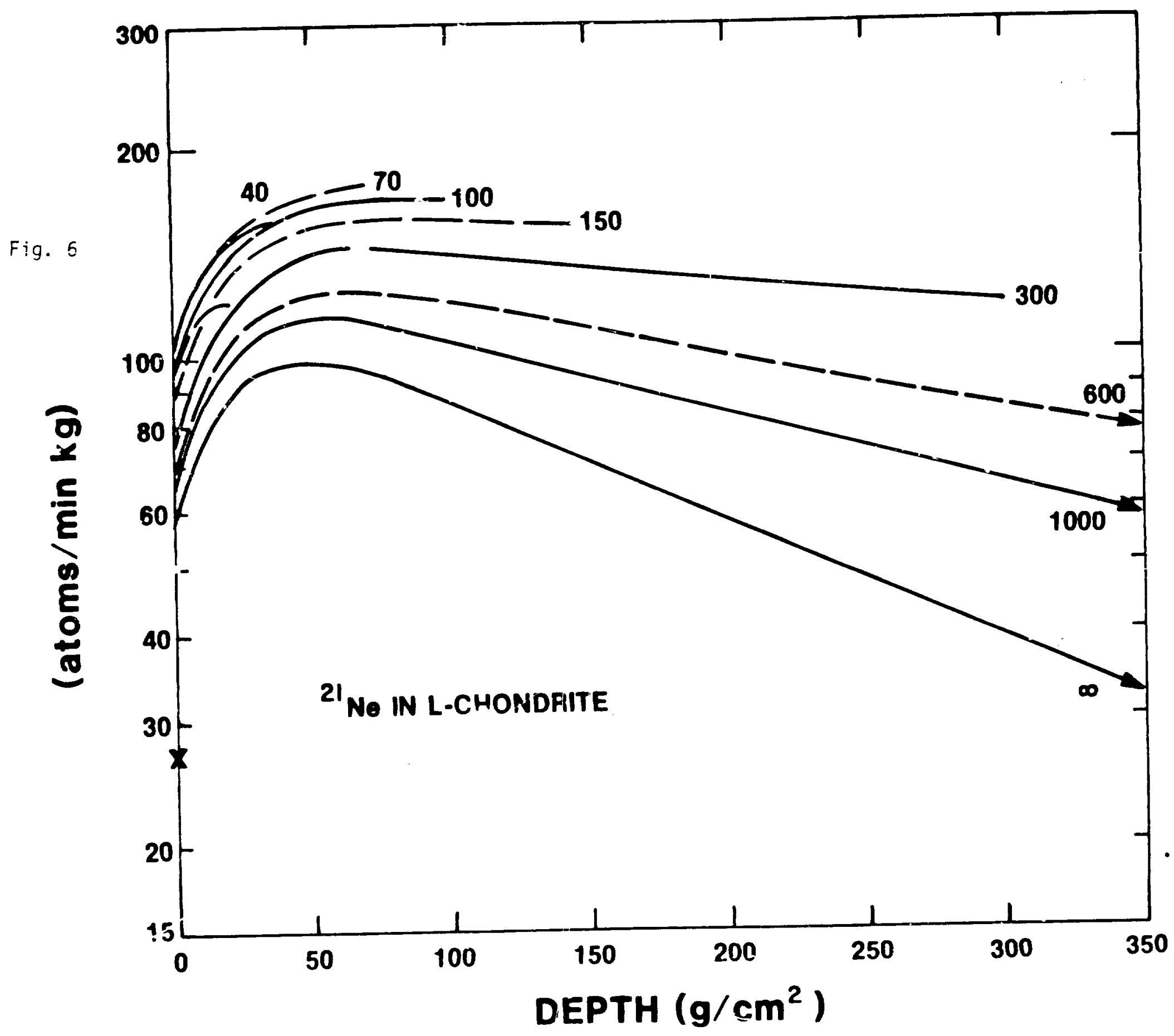




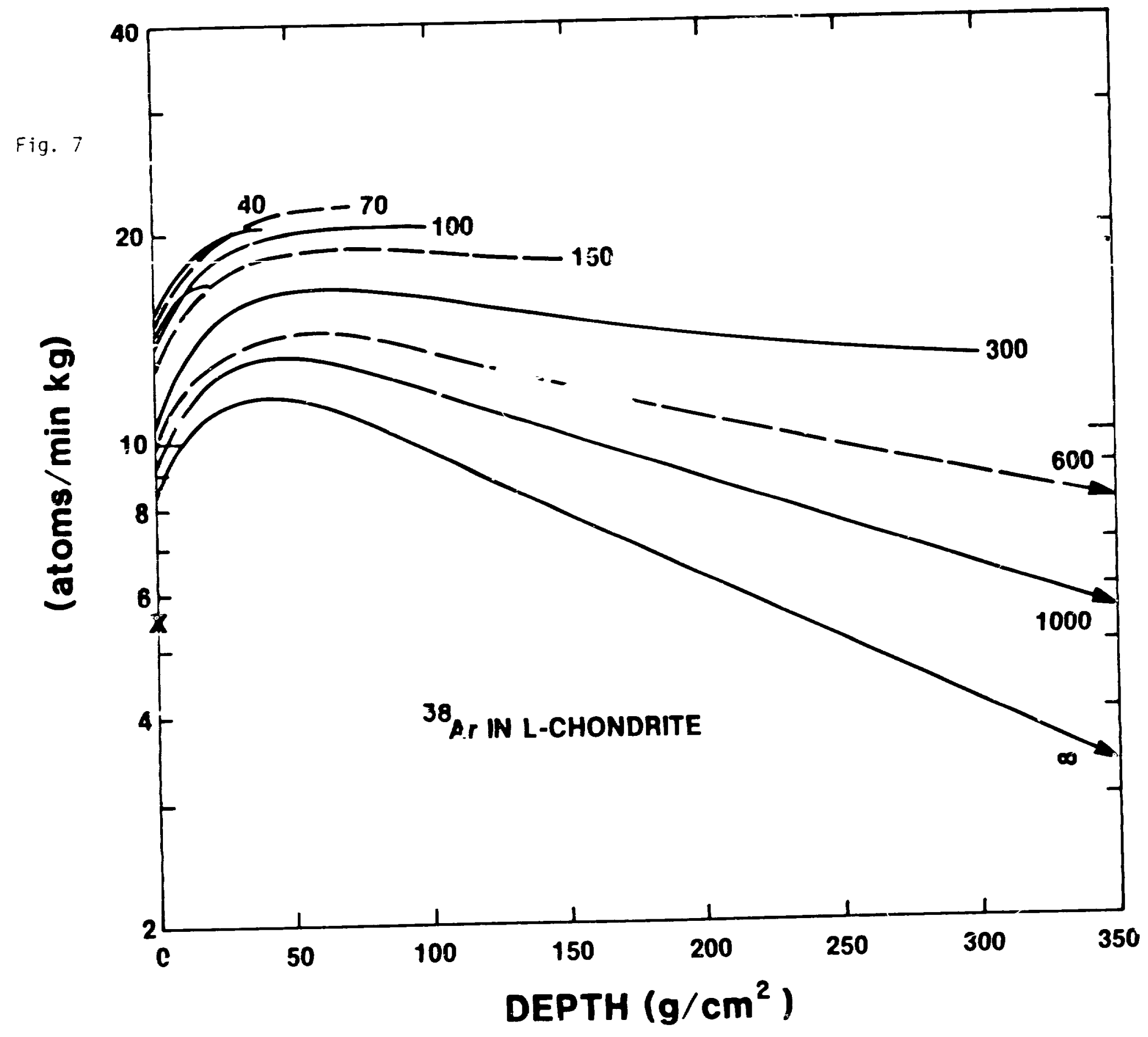

